OPEN ACCESS

Edited by:

Markus Haug,

Norwegian University of Science and

Technology, Norway

Reviewed by:

Morgane Bomsel,

Centre National de la Recherche

Scientifique (CNRS), France

Amanda B. Macedo,

George Washington University,

United States

*Correspondence:

Ole Schmeltz Søgaard

olesoega@rm.dk

Caroline Thue Hvilsom

201509955@post.au.dk

Specialty section:

This article was submitted to

Viral Immunology,

a section of the journal

Frontiers in Immunology

Received: 03 May 2021 Accepted: 03 September 2021 Published: 23 September 2021

Citation:

Hvilsom CT and Søgaard OS (2021) TLR-Agonist Mediated Enhancement of Antibody-Dependent Effector Functions

as Strategy For an HIV-1 Cure.

Front. Immunol. 12:704617.

doi: 10.3389/fimmu.2021.704617

\section{TLR-Agonist Mediated Enhancement of Antibody-Dependent Effector Functions as Strategy For an HIV-1 Cure}

\author{
Caroline Thue Hvilsom ${ }^{1 *}$ and Ole Schmeltz Søgaard ${ }^{1,2 *}$ \\ 1 Department of Clinical Medicine, Aarhus University, Aarhus, Denmark, ${ }^{2}$ Department of Infectious Disease, Aarhus University \\ Hospital, Aarhus, Denmark
}

Background: The current treatment for HIV-1 is based on blocking various stages in the viral replication cycle using combination antiretroviral therapy (ART). Even though ART effectively controls the infection, it is not curative, and patients must therefore continue treatment life-long.

Aim: Here we review recent literature investigating the single or combined effect of toll-like receptor (TLR) agonists and broadly neutralizing antibodies (bNAbs) with the objective to evaluate the evidence for this combination as a means towards an HIV-1 cure.

Results: Multiple preclinical studies found significantly enhanced killing of HIV-1 infected cells by TLR agonist-induced innate immune activation or by Fc-mediated effector functions following bNAb administration. However, monotherapy with either agent did not lead to sustained HIV-1 remission in clinical trials among individuals on long-term ART. Notably, findings in non-human primates suggest that a combination of TLR agonists and bNAbs may be able to induce long-term remission after ART cessation and this approach is currently being further investigated in clinical trials.

Conclusion: Preclinical findings show beneficial effects of either TLR agonist or bNAb administration for enhancing the elimination of HIV-1 infected cells. Further, TLR agonistmediated stimulation of innate effector functions in combination with bNAbs may enhance antibody-dependent cellular cytotoxicity and non-human primate studies have shown promising results for this combination strategy. Factors such as immune exhaustion, proviral bNAb sensitivity and time of intervention might impact the clinical success.

Keywords: toll-like receptor agonists, broadly neutralizing antibodies, HIV-1 cure, effector mechanisms, ADCC, HIV reservoir, NK cells

\section{INTRODUCTION}

Overwhelming progress has been made in preventing and treating human immunodeficiency virus 1 (HIV-1). Antiretroviral therapy (ART) can now effectively control viral replication, prevent the development of acquired immunodeficiency syndrome (AIDS), reduce risk of transmission and restore normal life expectancy (1). However, during the early phase of primary infection, HIV-1 integrates into the host genome establishing a latent reservoir that persists even after decades of ART. The reservoir persists 
primarily in long-lived infected $\mathrm{CD} 4+\mathrm{T}$ cells containing transcriptionally silent, but replication competent provirus, that goes undetected by the host immune system and after ART cessation generally leads to rebound viremia (2-5). Life-long compliance to ART is therefore a requirement for virologic control until alternative treatment strategies can be developed enabling sustained ART-free virologic remission or complete eradication of the viral reservoir (6). One strategy aimed at eliminating the viral reservoir, hypothesize that the administration of latency reversing agents (LRAs), will reactivate HIV-1 transcription in latently infected cells, subsequently making cells sensitive to immune-mediated killing (7). However, thus far this strategy has not been effective in eradicating the HIV-1 reservoir.

During acute HIV-1 infection, an initial decline in plasma viremia occurs prior to the development of adaptive immunity, indicating that the innate immune system plays a potential role in controlling initial disease progression (8). It has been demonstrated that the priming of innate effector cells such as natural killer (NK) cells enhance their ability to recognize and eliminate infected cells, suggesting that agents which prime innate NK-mediated immunity can augment HIV-1 cure therapies (8). Toll-like receptor (TLR) agonists specifically TLR 7 and 9 agonists are mainly expressed on plasmacytoid dendritic cells (pDCs) and B cells and trigger not only innate immune functions but also plays a role in initiating the adaptive response. They are therefore favored in this strategy as they both function as LRAs and immune stimulatory compounds (9).

Broadly neutralizing antibodies (bNAbs) are able to engage both adaptive and innate immune responses. An important mechanism for eliminating infected cells is mediated by antibody-dependent effector functions such as antibody-dependent cellular cytotoxicity (ADCC). Some HIV-1 positive patients have been shown to develop broad serologic neutralization activity against conserved viral epitopes after a period of two to four years $(10,11)$. Multiple bNAbs have now been identified and are currently being evaluated for their ability to directly target HIV-1 infected envelope (Env) expressing cells, thus facilitating infected cell elimination through $\mathrm{Fc} \gamma$ receptor $(\mathrm{Fc} \gamma \mathrm{R})$-dependent effector mechanisms.

Consequently, in this review we explore the current literature for evidence that stimulation of innate immune cells by TLR agonists in combination with bNAb administration may induce sustained remission in HIV-1 infected patients after ART cessation. We detail the current knowledge on the single and combined effect of TLR agonists 7 or 9 and bNAbs from preclinical and clinical studies. The present review focuses on the involved mechanisms including TLR agonist-induced innate immune activation, bNAb-binding to infected cells, ADCC capacity, viral reservoir size, and time to viral rebound during analytical treatment interruption (ATI).

\section{IMMUNOMODULATORY PROPERTIES OF TLR7 AND 9 AGONISTS}

\section{Ex Vivo/In Vitro Studies}

Four preclinical studies evaluated the ability of TLR7 or 9 agonists to enhance immune effector functions and HIV-1 transcription in latently infected cells (Table 1). A study by Bam et al. (12) investigated the ability of the TLR7 agonist GS-9620 to inhibit $\mathrm{HIV}-1$ replication in vitro in both peripheral blood mononuclear cells (PBMCs) and isolated CD4+ T cells from donors infected with luciferase reporter HIV-1. GS-9620 showed antiviral activity in ex vivo HIV-1 infected PBMCs when pre-stimulated for 48 hours with GS-9620 prior to infection, however GS-9620 was inactive against HIV-1 in purified CD4+ T cells. An increase in the production of interferon- $\alpha$ (IFN- $\alpha$ ) was observed in GS-9620-treated PBMCs and the co-treatment with IFN- $\alpha$-blocking antibodies reversed the HIV-1 inhibitory effect. Additionally, IFN- $\alpha$ production was detected in isolated pDCs treated with GS-9620.

In line with these findings, Tsai et al. (13) demonstrated that GS-9620 induced latent HIV-1 RNA production in PBMCs from HIV-1 infected donors with a 1.6-fold increase compared to vehicle controls. No increase of HIV-1 RNA was detected when isolated CD4+ $\mathrm{T}$ cells were stimulated directly which is not surprising given that CD4+ $\mathrm{T}$ cells do not express TLR7 at physiologically active levels. When PBMCs were co-incubated with antibodies against IFN- $\alpha$ receptors, no increase in HIV-1 RNA levels were detected suggesting that the activation of integrated proviruses is at least partially induced by IFN- $\alpha$.

Utilizing a primary cell model with $\mathrm{CD} 4+\mathrm{T}$ cells latently infected with the replication-competent HIV-1 strain, NL4.3, Macedo et al. (14) tested latency reversal abilities of the two TLR7 agonists GS-9620 and CL264. Latency reversal was evaluated with a combination of readouts by measuring the induction of viral p24 Gag protein and by the surface downregulation of CD4 expression by the viral genes Nef and Vpu. Neither of the tested TLR7 agonists were observed to directly reactivate latent HIV in CD4+ T cells when compared to untreated controls. However, supernatant from PBMCs previously stimulated with GS-9620 effectively reactivated latent HIV in JLAT10.6 cells. This JLAT10.6 cell line harbors the full-length viral DNA that is transcriptionally silent in the absence of external stimuli and unresponsive to the TLR agonists used in this study. When stimulated with cytokines such as tumor necrosis factor- $\alpha$ (TNF- $\alpha$ ), viral gene expression is activated, which can be measured by monitoring the expression of the reporter gene, GFP by flowcytometry (23). In order to identify the soluble factor(s) responsible for viral reactivation eight cytokines including IFN- $\alpha$ were tested. Contrary to Bam et al. (12) and Tsai et al. (13) only TNF- $\alpha$ was found to reactivate latent HIV even though increased levels of IFN- $\alpha$ were secreted from PBMCs stimulated with GS-9620. Additionally, supernatants treated with antibodies against TNF- $\alpha$ were unable to reactivate latent HIV in JLAT10.6 cells. Previous studies have indicated a cross-regulation between TNF- $\alpha$ and IFN- $\alpha$ (24), hereby suggesting that IFN- $\alpha$ is able to induce immune activation and subsequent production of TNF- $\alpha$ (14). In addition, Macedo et al. (14) found IFN- $\alpha$ secretion closely correlated with the ability of supernatants to reactivate latent HIV underlining the possibility of a synergistic effect on HIV reactivation with these two cytokines.

It is important to note, that Bam et al. (12) and Tsai et al. (13) used cells isolated from healthy donors and aviremic HIV-1 positive donors respectively, whereas Macedo et al. (14) used the JLAT10.6 cell line as target cells, which were clonally selected 
TABLE 1 | Studies investigating TLR7 and 9 agonists as LRAs and immune stimulators.

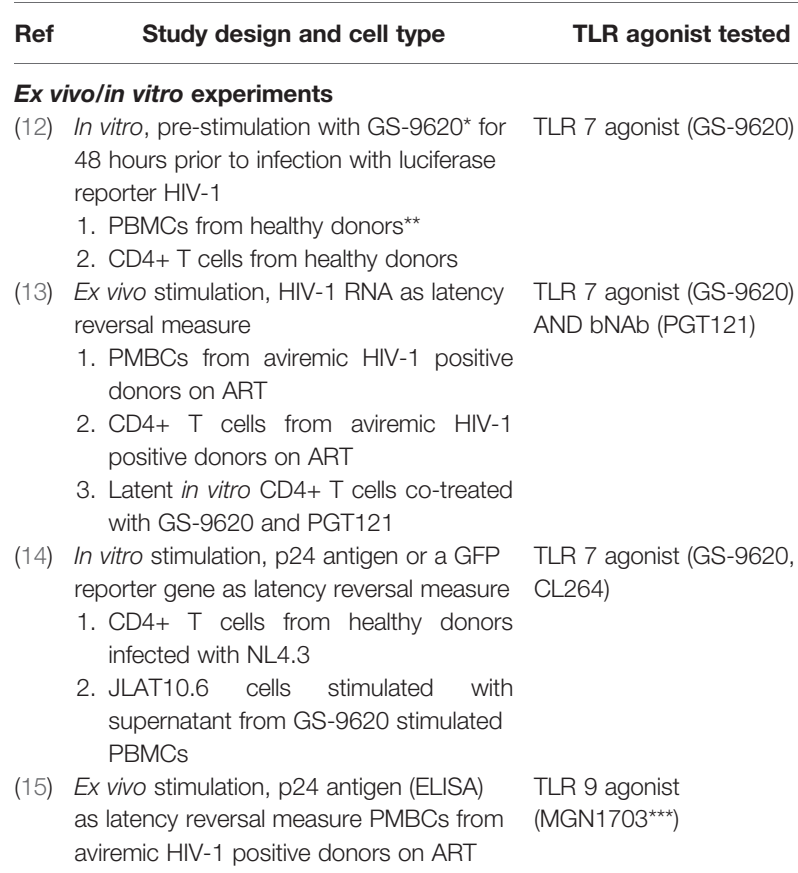

\section{Non-human in vivo studies}

(16) In vivo, NHP model 10 chronically SIVmac251-infected rhesus macaques on long-term ART:

- $\quad$ GS-9620 ( $n=5)$

- Control $(n=5)$

GS-9620 was administered every other week for a total of 10 doses

(17) In vivo, NHP model

21 chronically SIVmac251-infected rhesus macaques on long-term ART:

STUDY 1

- $\quad$ GS-986 $(n=4)$

- Control $(n=6)$

STUDY 2

- $\quad$ GS-986 $0.1 \mathrm{mg} / \mathrm{kg}(\mathrm{n}=3)$

- $\quad$ GS-9620 $0.05 \mathrm{mg} / \mathrm{kg}(\mathrm{n}=3)$

- $\quad$ GS-9620 $0.15 \mathrm{mg} / \mathrm{kg}(\mathrm{n}=3)$

- Control ( $n=2)$

10 doses of GS-986 or GS-9620 every other week followed by a 3-month resting period and then another 9 doses

(18) In vivo, NHP model

6 chronically SIVmac239X-infected rhesus macaques on long-term ART:

- GS-9620 ( $n=4)$

- Control $(n=2)$

12 doses of GS-9620 were administered approximately every other week followed by a resting period and then additional 5 doses (1a) HIV-1 replication

(1b) IFN- $\alpha$-level in supernatant from PBMCs post GS-9620 stimulation (2) HIV-1 replication

(1) Mean supernatant HIV1 RNA-level (2) Mean supernatant HIV1 RNA-level

(3) GS-9620+PGT121

(1) Latent HIV reactivation (2) Latent HIV reactivation

(1) IFN- $\alpha$-level in supernatant post MGN1703 stimulation (2) usRNA-level in CD4+ T cells extracted post MGN1703 stimulation

TLR 7 agonist (GS-9620)

Intervention:

$0.15 \mathrm{mg} / \mathrm{kg}$ GS-9620 OR

vehicle control

ATI: 1 month after last GS9620 dose

TLR 7 agonist (GS-9620,

GS-986)

Intervention:

STUDY 1

Dose escalation 0.1-0.3

$\mathrm{mg} / \mathrm{kg}$ GS-986

$\mathrm{OR}$ vehicle control

STUDY 2

GS-986 0.1 mg/kg OR GS-

96200.05 mg/kg OR GS-

$96200.15 \mathrm{mg} / \mathrm{kg}$

OR vehicle control

ATI: 2 weeks after last TLR

7 agonist dose

TLR 7 agonist (GS-9620)

Intervention:

0.15 or 0.05 mg/kg GS-

9620 OR vehicle control

ATI: approximately week

146 post infection

(3) Safety and tolerability
(1) Plasma cytokine levels

(2) Time to viral rebound

STUDY 1

(1a) Peripheral immune cell (1a) Transient CD69 upregulation on T, NK and B cells activation

(1b) Plasma cytokine levels

(2) Effect on plasma viremia

(3) Time to viral rebound

STUDY 2

(1) Efficacy of increased number of TLR 7 agonist doses

(1a) Peripheral immune cell activation

(1b) Plasma cytokine levels (1b) Transient increased levels of IFN- $\alpha$ and ISGs

(2) Effect on plasma viremia

(3) Time to viral rebound

(1) Increased levels of IFN- $\alpha$ and IL-6

No increase in TNF- $\alpha$, IFN- $\gamma$, IL-2

(2) No significant delay in time to viral rebound and all animals rebounded (> 50 SIV RNA copies $/ \mathrm{mL}$ ) within 2 weeks following ATI

(3) No adverse events or tolerability issues

STUDY 1

(1b) Increased levels of IFN- $\alpha$ 4/4 GS-986-treated animals

(3) No significant delay in time to viral rebound and all days following ATI

STUDY 2 aviremic for 700 days after ATI

(1a) No sign of CD4+ T cell activation

(2) No increase

(3) All animals rebounded within 4 weeks following ATI (1a) Inhibition

(1b) Increase

(2) No inhibition

(1) 1.6 median increase (100 nM) compared to controls $(P=0.03)$

(2) No increase

(3) GS-9620 enhanced PGT121-mediated killing of HIV+ CD4+ T cells

(1) No significant difference in \%p24+ cells (2) Significant difference in \%GFP+ cells compared to controls $(P<0.001)$

(1) Increase $(P=0.005)$

(2) 1.4-fold median increase $(P=0.036)$ when 2-fold stimulation (6 $\mathrm{nM}$ to $6 \mu \mathrm{M})$

(2) Transient plasma viremia < 1000 SIV RNA copies/mL in animals rebounded (> 50 SIV RNA copies $/ \mathrm{mL}$ ) within 7-10

(1) Two animals had no inducible viral reservoir and was 
TABLE 1 | Continued

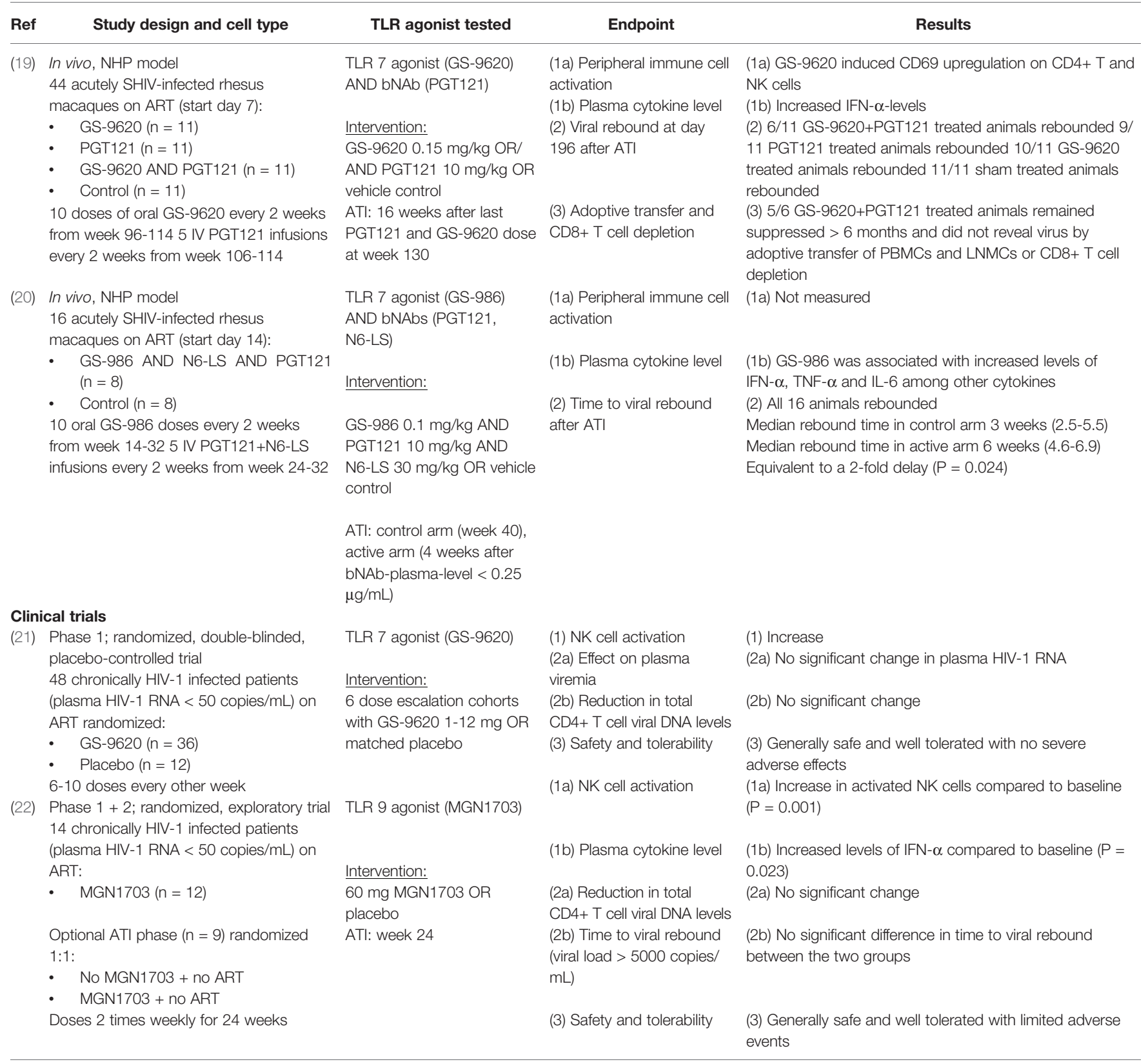

Most studies had multiple endpoints. The most relevant endpoints are outlined in this table; ${ }^{*} T L R 7$ agonist vesatolimod (GS-9620); * Healthy donors = healthy HIV-1 seronegative donors; ${ }^{* * *}$ TLR 9 agonist lefitolimod (MGN1703).

based on the ability to reactivate latent HIV by TNF- $\alpha$ stimulation (23). Despite discrepancies between applied methods and findings in the above studies, they all indicated that the latency reversing effect of GS-9620 on CD4+ T cells is being indirectly mediated by cytokine release from activation of mainly pDCs (9).

In an ex vivo model using PBMCs from aviremic $\mathrm{HIV}-1$ infected donors, Offersen et al. (15) assessed the capacity of the TLR9 agonist MGN1703 to enhance immune effector functions as well as HIV-1 transcription. The study found a variable magnitude of response among PBMC donors, but a significant increase in IFN- $\alpha$ release from stimulated PBMCs $(\mathrm{P}=0.005)$. CD4+ T cells isolated from MGN1703-incubated PBMCs also showed an enhanced transcription of HIV-1 unspliced RNA (usRNA) $(\mathrm{P}=0.036)$.

As reviewed in Hornung et al. (25) and Adib-Conquy et al. (26), TLR7 and 9 are primarily expressed on DCs and B cells, and therefore the observed activation of NK and T cells is mediated indirectly via cytokine release and cell-to-cell interaction (15). In accordance with the findings above, this implies that the optimal ex vivo model for assessing TLR7 and 9 agonists is PBMCs instead of just isolated CD4+ $\mathrm{T}$ cells which will likely underestimate the potential in vivo effect. 


\section{Non-Human Primate Studies}

Bekerman et al. (16) conducted a study with 10 simian immunodeficiency virus (SIV)-infected rhesus macaques on long-term ART allocated to receive either GS-9620 or vehicle control every other week for a total of 10 doses. ART was continued during GS-9620 administration until analytical treatment interruption (ATI) was initiated one month after the last GS-9620 dose. Peripheral immune cell activation and plasma cytokine levels were measured 24 hours after each dose and significant increases in plasma IFN- $\alpha$ levels post-dosing were seen in GS-9620-treated animals compared to controls.

The study also evaluated the effect of GS-9620 on the viral reservoir and found no significant difference between GS-9620treated animals and controls in total cell-associated viral DNA measured in PBMCs, lymph node mononuclear cells (LNMCs), and rectal biopsies. Additionally, there was no delay in time to viral rebound in GS-9620-treated animals compared to controls. All 10 animals rebounded within two weeks of starting the ATI.

Lim et al. (17) showed that GS-986 treatment in escalating doses was able to induce transient SIV plasma RNA blips $<1000$ copies/mL in four out of four virally suppressed rhesus macaques on ART compared to zero out of six controls. Plasma viremia returned to baseline ( $<50$ SIV RNA copies $/ \mathrm{mL}$ ) within four to seven days after GS-986 dosing. T, NK and B cell activation, measured as an increase in CD69 expression, was detected within 24 to 48 hours after GS-986 treatment and returned to baseline before the next dose. An average reduction of $75 \%$ of SIV DNA in CD4+ T cells isolated from PBMCs, gastrointestinal mucosa mononuclear cells (GMMCs) and LNMCs was observed in GS986-treated animals. Lastly, ART was discontinued to evaluate viral rebound kinetics, and viral rebound occurred in all animals within seven to 10 days with no significant difference in time to viral rebound being observed between GS-986-treated animals and controls. In a subsequent study, the same group tested the effect of an increased number of TLR 7 agonist doses and observed similar results. However, when assessing the viral reservoir, two TLR 7 agonist-treated animals were negative for SIV RNA induction in both PBMCs and LNMCs samples. The same two animals remained aviremic for more than 700 days after ART discontinuation whereas the remaining animals displayed rebound viremia within seven to 10 days. Adoptive transfer of PBMCs and LNMC from the aviremic animals did not induce de novo infection in naïve macaque recipients.

Del Prete et al. (18) were unable to reproduce results from Lim et al. (17) in a similar non-human primates (NHP) model. Six rhesus macaques were intravenously inoculated with SIVmac239X and treated with ART from day 13 post-infection. Seventy-five weeks after ART initiation animals were allocated to receive either 12 doses of GS-9620 (at 0.15 or $0.05 \mathrm{mg} / \mathrm{kg}$ ) or vehicle control by oral gavage. ART was continued for a total of 144 weeks.

GS-9620 was shown to induce upregulation of multiple interferon-stimulated genes (ISGs) as well as significantly higher levels of plasma cytokines (IFN- $\alpha$, IL-1RA, CXCL11) 24 hours post-dosing. The increase was transient and no significant difference between treatment groups was observed at before-dose time points. CD4+ $\mathrm{T}$ cells showed no increased activation following GS-9620 treatment, however 24 hours post-dosing GS-9620 induced significantly elevated CD38 expression (mean percentage of CD38+ increasing from $71 \%$ to $90 \%$ ) as well as increased co-expression of CD38 and HLA-DR on CD8+ T cells indicating a significant CD8+ T cell activation. No measurable increase in plasma viremia was observed with SIV $<15$ RNA copies/mL throughout the 12 doses of GS-9620 and no significant changes in transcriptional RNA levels in PBMCs, LNMCs or GMMCs was observed 24 or 48 hours post-dosing. All six animals rebounded within four weeks following ATI.

The reason for the conflicting findings between the two comparable NHP studies is not clear. In Del Prete et al. (18) animals were initiated on ART relatively early in infection (day 13) and were maintained on ART for 525 days prior to GS- 9620 initiation. In comparison Lim et al. (17) initiated ART at day 65 post ART initiation and continued ART for 437 days before starting GS-986 treatment. It is possible that the viral reservoir established in animals from Del Prete et al. was too small to result in reactivated virus causing measurable changes of plasma viral loads. However, no consistent increase in viral transcriptional levels, measured as PBMC and tissue RNA/DNA ratios, were detected, which would be expected if sufficient viral reactivation had occurred. The timing of ART initiation and intervention could potentially affect the establishment of the viral reservoir causing the conflicting findings. NHPs from Lim et al. were infected using a low-dose intrarectal challenge with the SIVmac251 strain, whereas NHPs from Del Prete et al. were infected intravenously with the SIVmac239X strain. The different administration route as well as viral strain could also have contributed to the conflicting results. The relationship between ART initiation timing and duration, intervention timing and the established viral reservoir should be further investigated in future studies in NHPs.

Results from preclinical studies investigating the latency reversing effects of TLR7 or 9 agonists have showed promising evidence for a dual effect towards HIV-1 eradication. Partly by latency reversal in infected cells dependent on either a type I IFN production $(12,13,15-17)$ or by TNF- $\alpha$ production (14) as well as enhanced Fc-mediated immune functions (13). However, as we discuss in the next section, clinical trials investigating the single effect of TLR agonists have not been able to show a sustained reduction in the size of the viral reservoir $(21,22)$.

\section{Clinical Trials}

In a randomized, placebo-controlled trial conducted by Riddler et al. (21), 48 individuals were assigned to receive six to 10 doses of GS-9620 (1-12 mg) or placebo every other week in matched dose escalation cohorts. GS-9620 was generally safe and well tolerated with no adverse events leading to treatment discontinuation. GS-9620 did not induce plasma viremia and no significant differences in usRNA or total HIV-1 DNA in CD4+ T cells were observed between groups. GS-9620 treatment was associated with the induction of serum cytokines, however IFN- $\alpha$ mean levels were below the detection limit at most time points and generally only detectable for GS-9620 doses $\geq 6 \mathrm{mg}$. The study observed a dose-dependent induction of ISGs after 
GS-9620 administration of $4 \mathrm{mg}$ or more with the greatest induction in the $8 \mathrm{mg}$ group 24 hours post-dose, as well as an increase in the frequency of CD69+ NK cells at GS-9620 doses of 6 and $8 \mathrm{mg}$. Notably, the dose required to induce an ISG response $(\geq 4 \mathrm{mg}$ ) was lower than that required for detection of serum IFN- $\alpha$ levels ( $\geq 6 \mathrm{mg}$ ). GS-9620 (Vesatolimod) is currently being evaluated for safety, tolerability and antiviral activity in HIV-1 viremic controllers on ART and subsequently during ATI (NCT03060447).

Vibholm et al. (22) conducted a 24-week exploratory study with 14 chronically infected HIV-1 patients on ART. Patients received $60 \mathrm{mg}$ of the TLR 9 agonist MGN1703 two times weekly for 24 weeks followed by an optional ATI period. ATI participants were randomized to discontinue either ART and MGN1703 treatment simultaneously at week 24 or only ART while continuing MGN1703 treatment for an additional four weeks. The study found a systemic type I IFN response and enhanced activation of $\mathrm{NK}$ cells that was sustained for the duration of MGN1703 treatment. However, 24 weeks of MGN1703 treatment did not significantly reduce total HIV-1 DNA, usRNA or replication competent HIV-1 in CD4+ T cells in this cohort or delay time to viral rebound.

\section{BROADLY NEUTRALIZING ANTIBODIES AS MEDIATORS OF ADCC}

We identified five preclinical studies evaluating the ability of different bNAbs to eliminate HIV-1 infected lymphocytes through NK-mediated ADCC. Profiling of bNAb-binding capacity, neutralization breadth and ADCC activity were evaluated using either cell lines or primary CD4+ T cells and either laboratory (lab)-adapted HIV-1 strains or primary viral isolates from HIV-1 positive patients. A summary of the ex vivo, in vitro and in vivo studies investigating ADCC-mediated elimination of HIV-1 infected cells by bNAbs and their main findings are shown in Table 2.

\section{Ex Vivo/In Vitro Studies}

There is no consensus assay for evaluating ADCC activity in an HIV setting and the lack of a standardized method to determine the viability of infected target cells makes it challenging to directly compare results across studies. Dupuy et al. (27) designed a novel flow-based measurement of ADCC using annexin $\mathrm{V}(\mathrm{AnV})$ staining of target cells and compared this method with previous ADCC assays. The AnV-assay was significantly more sensitive for the detection of target cell elimination, detecting both dying and dead cells, when compared with the Live/Dead (L/D) staining method, that only detected dead cells. This suggests that studies using the L/D method may underestimate the extent of ADCC. Furthermore, the AnV-assay is specific for target cells expressing HIV-1 Env and was shown to be more sensitive than the ADCC-GranToxiLux (ADCC-GTL) assay, which indirectly detects apoptosis by measuring the delivery of granzyme B to target cells (37). The rapid fluorometric ADCC (RFADCC) assay has been widely used to measure ADCC, however this assay quantifies membrane exchange between target and effector cells rather than ADCC activity directly $(38,39)$. The ADCC-AnV assay measures ADCC by identifying and quantifying dying and dead cells with a sensitivity superior to previous methods, hereby making it an advantageous method for evaluating ADCC activity in future studies.

Applying this novel method of ADCC detection, Dupuy et al. (27) conducted a comprehensive study using CEM cells infected with the laboratory HIV-1 strain, NL4.3. Antibody binding capacity and ADCC activity of a panel of bNAbs were evaluated using the $\mathrm{AnV}$ staining method against both p24 confirmed newly infected (niCEM) cells, bystander (byCEM) cells with shedded gp120 and non-infected (nCEM) cells, to evaluate the bNAb activity towards genuinely infected cells versus bystander cells (40). ADCC activity was found to be associated with binding capacity for all tested bNAbs with the exception of $2 \mathrm{G} 12$ that bound the HIV-1 Env protein on both niCEM and byCEM with a high mean fluorescence intensity (MFI) without inducing ADCC. 2 G12 is suggested to have an unusual domain-swapped configuration which may affect the ability of this bNAb to interact with Fc receptors and support ADCC $(41,42)$. This association was supported by a significant correlation between frequency and MFI of bNAb-binding to Env and the frequency of AnV+ niCEM cells generated in the ADCCAnV assay $(P=0.0003)$. The study importantly differentiates between ADCC detected towards genuinely HIV-infected cells and HIV-uninfected bystander cells when conducting assays, otherwise risking an overestimation of the ability of antibodies to mediate ADCC.

Bruel et al. (28) investigated antibody binding and ADCC activity of 10 bNAbs against CEM cells infected with the laboratory strains NLAD8 or NL4.3 and Transmitted/Founder (T/F) viruses. In line with the results from Dupuy et al. (27), most antibodies triggered a significant elimination of CEM cells infected with the lab-adapted HIV-1 strains while also exhibiting a significant correlation between binding potency and NK-mediated killing activity. When the panel of bNAbs was evaluated against CEM cells infected with T/F viruses, bNAbs had significantly lower binding and a reduced killing activity against these target cells when compared to NLAD8 or NL4.3 infected cells (28).

Furthermore, the study evaluated binding and ADCC activity of bNAbs against reactivated CD4+ $\mathrm{T}$ cells isolated from aviremic HIV-1 positive patients on ART and found considerable heterogeneity in the level of Env expressed on reactivated cells associated with a variable susceptibility to ADCC. Similarly, von Bredow et al. (29) observed that NL4.3-infected cells were generally more sensitive to ADCC, both in terms of the number of ADCC active antibodies and the magnitude of responses when compared to cells infected with a primary HIV-1 strain.

ADCC-mediated elimination of infected cells relies on interaction between the $\mathrm{Fc}$ region of bNAbs and the $\mathrm{Fc} \gamma \mathrm{R}$ on effector cells. This interaction can be demonstrated by introducing mutations in Leu234Ala and Leu235Ala (commonly called LALA mutations) which more or less eliminates human cell 
TABLE 2 | Studies investigating ADCC elimination of HIV-1 infected cells by bNAbs.

\begin{tabular}{llll}
\hline $\begin{array}{l}\text { Ref } \\
\text { type }\end{array}$ & ENady design and cell & Endenge virus \\
\hline
\end{tabular}

\section{Ex vivo/in vitro experiments}

(27) Ex vivo, ADCC assay (AnV staining) CEM cells*, NK cells purified from healthy donors $^{\star *}$

(28) Ex vivo/in vitro, ADCC assay (L/D staining)

CEM cells, PBMCs from aviremic HIV-1 infected donors, NK cells purified from healthy donors
HIV-1 NL4.3

b12, VRC01, NIH45-46, 3BNC117, PG16, PGT121, 101074, $2 \mathrm{G} 12$

(1) Binding and ADCC activity against niCEM and byCEM cells
(1)HIV-1 NLAD8, NL4.3 (2) $T / F$ viruses virus

HIV-1 NL4.3 HIV-1JRFL SHIV $_{\text {AD8-EO }}$ (3)Reactivated patient b12, b6, VRC01, PGV04, 3BNC117, PG9, PG16, PGT126, 4E10, 10E8 PGT121, 10-1074, 2G12, 2F5,

VRC01, NIH45-46, 3BNC117, 8ANC195, 10E8, 4E10 kill lab-strain HIV-1 infected CEM cells

(2) Binding and ADCC activity against various $\mathrm{T} / \mathrm{F}$ virus CEM cells (3) Binding and ADCC activity against reactivated $\mathrm{HIV}-1$ infected CD4+ T cells (1) ADCC activity against infected CEM cells

(2) bNAb-binding and ADCC
(30) In vitro, ADCC assay (HIV- HIV-1 NL4.3 10 $1 \mathrm{Gag}+)$ primary HIV-1 PBMCs and NK cells from healthy donors clade B, 2 clade C, 2 clade D)

VRC01, NIH45-46, 3BNC117, PG9, PGT145, PG16, PGT121, 2G12, 2F5, 4E10

Control: F105

Reactivated patient virus from eight donors

PBMCs and NK cells from healthy donors, haNK cells ${ }^{\star \star \star *}$

Non-human in vivo studies

(32) In vivo, humanized mice model

Mice injected with PBMCs from a HIV-1 positive donor $(n=10)$

Mice with PBMCs from a HIV-1 positive and negative donor $(\mathrm{n}=12)$

(33) In vivo, humanized mice model
VRC01, VRC07-523, 3BNC117, N6, PGT121, 2G12, 10-1074, PG9, 10E8, 10E8V4-V5R-100cF, 2F5, 4E10 Control: 4G2-Hu

(2) ADCC activity against primary HIV-1 infected CD4+ T cells

(1) bNAb-binding against reactivated reservoir virus infected CD4+ $\mathrm{T}$ cells

(2) ADCC activity against reactivated reservoir virus infected CD4+ T cells

Time until viral rebound (undetectable viremia < 1000 copies $/ \mathrm{mL}$ )

Disappearance of Gag + cells PGDM1400, CAP256.VRC26.25,

\section{Reactivated patient 10-1074} virus from one donor

\section{Control: 10-1074-FcR ${ }^{\text {null** }}$}

3BNC117, 10-1074

HIV-1YU2

$\mathrm{HIV}_{2 \mathrm{C} 1}$

$\mathrm{HIV}_{2 \mathrm{C} 5}$

$\mathrm{HIV}_{2 \mathrm{D} 3}$

$\mathrm{HIV}_{2 \mathrm{E} 5}$
(1) All bNAbs that bound niCEM cells supported ADCC except 2G12 ( $P=0.003)$

Env-level on byCEM cells was insufficient to cause robust ADCC

(1) $8 / 12$ bNAbs induced FcyRIII signalling in NLAD8-infected cells (similar for NL4.3, except V3-specific bNAbs) Most bNAbs triggered significant disappearance of infected cells (20$50 \% \downarrow$ Gag + cells)

(2) $\downarrow$ Ability of bNAbs to bind and induce ADCC in cells infected with $\mathrm{T} / \mathrm{F}$ viruses compared with lab strain (NLAD8)

(3) Heterogeneity of reactivated cells associated with variable susceptibility to ADCC

(1) $12 / 14$ bNAbs induced significant lysis of NL4.3-infected cells (except 2F5, 4E10) 9/14 bNAbs induced significant lysis of HIV-1JR-FL -infected cells (except MPER, 2G12 and b6) (2) bNAb-binding correlated with ADCC activity for all three viruses, strongest for HIV-1JR-FL $(P<0.0001)$

Neutralization significantly correlated with ADCC for all tested viruses

(1) Significantly enhanced bNAb recognition of surface HIV-1 Env on CD4+ T cells with antibodies PG9, PGT145, PG16, 2 G12 compared to control

High variability of antibody recognition of target cells infected with different clades

(2) PG9 exhibited significant elimination of target cells $\downarrow 16.1 \%(P=0.0312)$

Recognition of HIV-1 infected CD4+ T cells was significantly correlated with ADCC activity (1) CD4bs Abs (except VRC01) exhibited cell binding breath of $83-89 \%$ of viral isolates, MFI ratios 2-4

V3 glycan antibodies exhibited cell binding breath of $42-75 \%, \mathrm{MFI}>5$

(2) Significant additional elimination of infected cells with the bNAb-addition

Moderate correlation between bNAb-binding of infected cells and ADCC

Untreated mice (12/12) displayed viremia after week 1

Viremia in mice treated with 10-1074 at week 1 (0/10, $\mathrm{P}<0.0001)$, week 2 (0/9, $\mathrm{P}<0.0001)$, week $3(0 / 8, P=0.005)$, week $4(3 / 6, P=$ 0.036)

Mice treated with 10-1074-FcR ${ }^{\text {null }}$ week 2 $(6 / 13)$

HIV-1 YU2 $_{\text {-infected cells reduced in mice treated }}$ with 3BNC117 $(P<0.005)$ and both 3BNC117 and 10-1074 $(P<0.001)$ compared to control Similar results with primary strains $(P<0.05)$ 
TABLE 2 | Continued

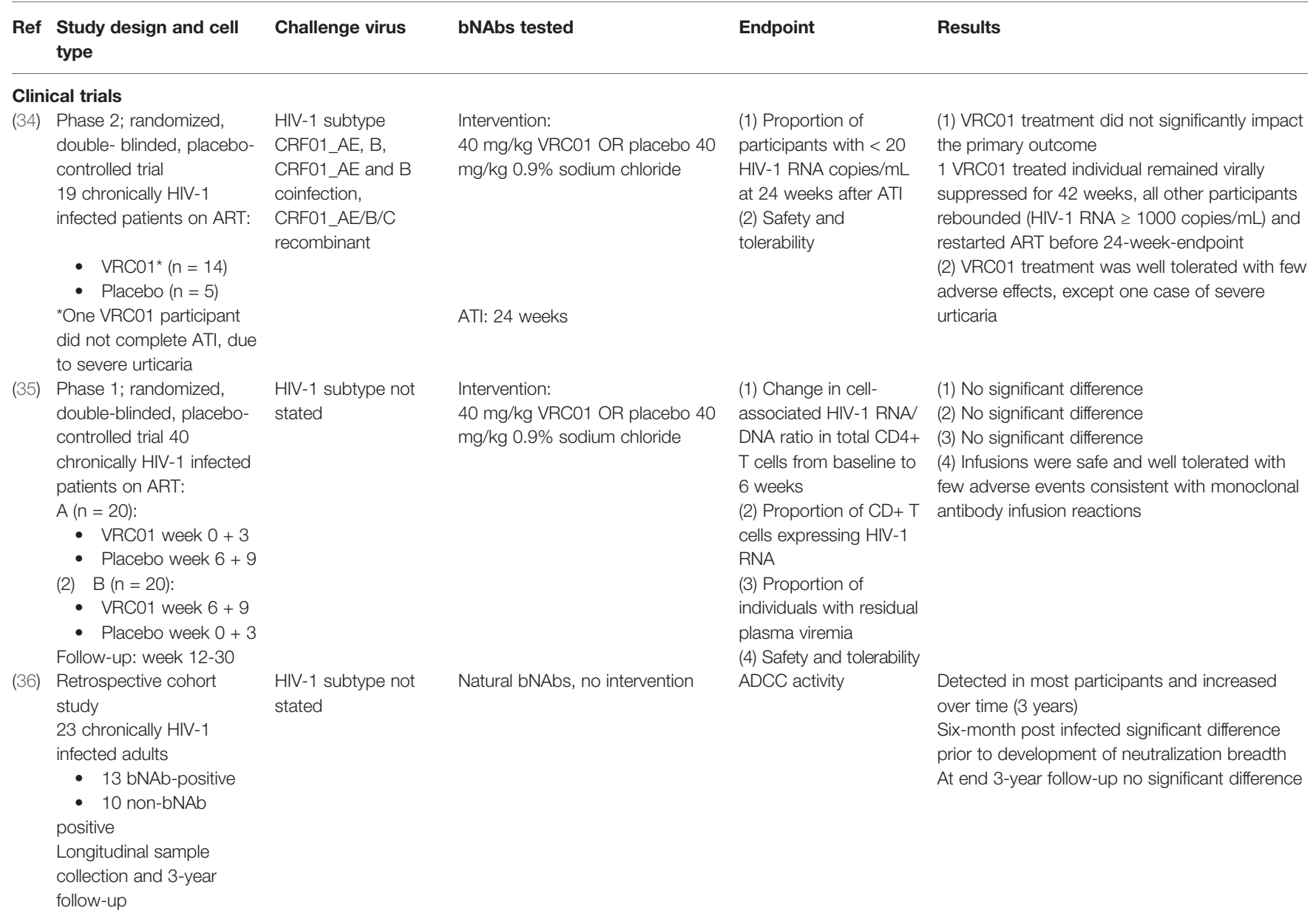

Most studies had multiple endpoints. The most relevant endpoints are outlined in this table; ${ }^{*}$ CEM.NKR.CCR5 cells; ${ }^{* *} H$ ealthy donors = healthy HIV-1 seronegative donors; ${ }^{* * *}$ Mutated FC region; ${ }^{* * * *}$ Enhanced for ADCC.

FcyRIII binding (43). This indicates that the difference in killing efficacy may be caused by changes in antibody binding and the availability of the Fc region when bound to infected cells (28).

Some uncertainty persists with regards to bNAbs binding of free virus versus cell-bound HIV Env. Mujib et al. (30) observed a lack of binding of primary HIV-1 infected CD4+ T cells with the bNAbs VRCO1, 3BNC117 and NIH45-46 suggesting a different conformation of the HIV-1 Env on the surface of infected CD4+ $\mathrm{T}$ cells compared with cell-free viruses that these antibodies have been demonstrated to efficiently neutralize $(28,29)$. Moreover, von Bredow et al. (29) described instances of ADCC in the absence of detectable neutralization.

Multiple in vitro/ex vivo studies investigating both laboratory and primary viral isolates observed a difference in susceptibility to ADCC (28-30). In general, studies report clinical viral isolates to be less sensitive to bNAbs than laboratory strains $(44,45)$. These observations underline the limitation in directly correlating results from experiments exclusively using laboratory strains to the physiological conditions in vivo (46). In addition, the use of primary CD4 $+\mathrm{T}$ cells as target cells in assays instead of cell lines has been suggested to best represent the availability for antibody binding in vivo as these cells express Env on their surface in its native conformation (30). Likewise, the use of primary NK cells best represents the in vivo effect of ADCC (30).

When comparing ADCC assays performed with 36 viral strains isolated from eight patients undergoing ART, Ren et al. (31) found both inter- and intraindividual variability. This underscores the importance of tailoring possible future antibody treatment strategies to match the patient's distinct viral reservoir and the limitation of using any single antibody as a treatment.

Mujib et al. (30) investigated 11 different HIV-1 strains representing clades (A-D) and found a significant interclade variation of binding capacity. This suggests that results from studies only investigating one HIV-1 clade, such as the study by Ren et al. (31) with a predominant North American clade B infected cohort, are not directly comparable to populations in which infection with non-B clades dominate.

Most in vitro/ex vivo studies found that bNAbs significantly enhanced the elimination of infected cells by ADCC and that ADCC activity correlated with binding and neutralization for 
each virus tested. The findings indicate that these functions overlap when testing antibodies with matched IgG1 Fc domains (27-30). However, Ren et al. (31) found the correlation between infected cell binding and ADCC to be weak, underlining that binding should not be considered the only measure of ADCC activity.

ADCC is considered primarily to be mediated by NK cells via FcyRIIIa, even though other immune cells, e.g., monocytes and granulocytes also express Fc $\gamma$ receptors capable of ADCC (39, 47). An increasing amount of literature suggests that monocytes can function as potential mediators of ADCC in the context of HIV infection with similar levels of infected cell killing compared with NK cells (48-50).

ADCC has mainly been studied using IgG antibodies targeting gp120 of the HIV-1 Env, rendering the effects of gp41 specific antibodies as well as IgA isotype antibodies elusive. A study by Duchemin et al. (51) found that 2F5-IgA a gp41 specific bNAb modified from 2F5-IgG - was able to engage FcoRI on human monocyte effector cells and enhance ADCC mediated killing of HIV-1 clade A and B infected target cells. When 2F5-IgA was combined with the IgG isotype bNAbs, 2F5-IgG or 10E8-IgG enhanced target cell lysis by ADCC was observed. However, other studies, including the RV144 clinical trial, have described vaccine-induced gp120-specific IgA to block gp120-specific IgG-binding sites, hereby attenuating IgGmediated ADCC $(52,53)$. Tomaras et al. used NK cells that do not express the Fc $\alpha$ RI which is essential for IgA-mediated ADCC and were therefore unable to induce IgA-mediated ADCC despite of efficient IgA-binding to infected cells, thus blocking IgG-binding and ADCC activity in this study.

Future studies should consider other immune cells, such as monocytes as effector cells in ADCC studies as well as further elucidate the effect of IgA isotype bNAbs on ADCC efficacy in relation to $\mathrm{IgG}$.

\section{In Vivo Studies}

A study by Flerin et al. (32) observed a significantly delayed time to viral rebound after the administration of the bNAb 10-1074 compared to treatment with a control-bNAb in immunodeficient mice that were intra-splenically injected with PBMCs from a long-term ART suppressed HIV-1 infected donor. This finding suggests that the 10-1074 treatment reduced the population of replication-competent latently infected cells through Fcmediated effector mechanisms. Lu et al. (33) investigated the effect of the bNAb 3BNC117 alone or in combination with 101074 in a humanized mice model and also found a significant reduction of the number of HIV-1 infected cells $(\mathrm{P}<0.005)$.

\section{Clinical Trials}

Crowell et al. (34) conducted a randomized, placebo-controlled trial evaluating the effect of VRC01 (bNAb) administration on time to viral rebound during ATI in adults who began ART during acute HIV infection. $23 \mathrm{HIV}-1$ infected patients were enrolled of which 18 received at least one infusion of VRC01 or placebo every three weeks for up to 24 weeks during ATI. One VRC01 patient achieved the primary endpoint of less than 20 HIV-1 RNA copies/mL at 24 weeks after ATI and remained virally suppressed for 42 weeks. All other patients experienced viral rebound and restarted ART before the 24-week-endpoint highlighting both the limitations of single bNAb treatment and perhaps the potency and limited breath of VRC01.

Riddler et al. (35) reported findings from a randomized, placebo-controlled trial including 40 chronically HIV-1 infected individuals on ART. In two study-arms, VRC01 or placebo were administered at entry and week three and alternating the treatments at week six and nine. In agreement with findings from Crowell et al., VRC01 did not have a significant impact on neither HIV-1 RNA or DNA levels, cellular HIV-1 RNA/DNA ratio, HIV-1 plasma viremia or stimulated virus production from total CD4+ T cells.

A retrospective cohort study performed by Richardson et al. (36) evaluated samples collected over a period of three years from HIV-1 infected participants in the CAPRISA acute infection cohort. Thirteen individuals who had developed bNAbs were matched with 10 non-bNAb-positive controls with similar viral levels. ADCC was detected in the majority of participants early in infection and increased over time throughout the three-year follow-up period. Six-months post-infection, the authors found significantly higher levels of antibody-dependent complement deposition (ADCD) and cellular trogocytosis (ADCT) among $\mathrm{bNAb}$ compared to non-bNAb-positive individuals that correlated with antibody binding to $\mathrm{C} 1 \mathrm{q}$ and FcyRIIa. In relation to neutralization breadth, ADCC activity did not differ between the two groups and no difference was seen at the threeyear follow-up endpoint $(33,36)$.

Although some doubt has been raised regarding the importance of Fc-mediated functions in one study that found Fc dependent functions partially redundant when testing the bNAb PGT121 (54), several other studies have demonstrated enhanced ADCC elimination of HIV-1 infected cells. However, the very low levels of HIV-1 Env expression on latently infected cells during long-term ART may limit ADCC and thereby the therapeutic effect of bNAbs. Studies in HIV-1 infected patients (34-36) have indicated that monotherapy with the bNAbs VRC01, 3BNC117 does not reduce the size of the latent reservoir when patients are on concomitant ART. A few bNAb participants were reported to have achieved long-term control of viremia during subsequent ATI but the clinical trials were limited by small population sizes and lack of a control group. Thus, there is not enough evidence to support that antibody-dependent effector mechanisms induced by monotherapy with bNAbs leads to post-treatment control when ART is stopped.

\section{COMBINING bNAbs IN HIV-1 CURE}

The effects of bNAbs can be mediated both by neutralization and by Fc-mediated effector functions such as ADCC. Combining two or more bNAbs, targeting multiple epitopes on the HIV Env, may provide broader coverage and passive protection against circulating HIV strains compared to a single antibody. By extension it can be proposed that similar combinations of bNAbs in relation to ADCC will ensure the broadest recognition and elimination of infected cells. Cohen et al. (55) 
investigated safety and pharmacokinetics of combined infusions with the bNAbs 3BNC117 and 10-1074 in healthy adults. Participants were randomized to receive either one infusion of 3BNC117 immediately followed by $10-1074$ at $10 \mathrm{mg} / \mathrm{kg}$, three infusions of 3BNC117 followed by $10-1074$ at $3 \mathrm{mg} / \mathrm{kg}$ or $10 \mathrm{mg} /$ $\mathrm{kg}$ every eight weeks or placebo. Antibody concentrations were measured by two different methods, ELISA and the TZM-bl neutralization assay, with general concordance between the two. The mean elimination half-lives for 3BNC117 and 10-1074 were found to be $16.4 \pm 4.6$ days and $23.0 \pm 5.4$ days, respectively and no serious adverse events were observed. Of note, no association between elimination half-life and dose level administered, or single or repeated doses for either antibody was observed $(\mathrm{P}>$ $0.05)$. 3BNC117 and 10-1074 have previously been shown to suppress viremia in HIV-1 infected individuals, when administered alone and as single or repeated doses ranging from 1 to $30 \mathrm{mg} / \mathrm{kg}(56,57)$. Cohen et al. compared ELISA data from HIV-uninfected individuals from these two studies receiving either $3 \mathrm{BNC117}$ or $10-1074$ with data of participants from their current study receiving the combination. Single or combined administration of the antibodies did not significantly affect the elimination half-life of either antibody, 3BNC117 (mean half-life: single $19.18 \pm 7.08$ days $v s$. combined $16.4 \pm$ 4.6 days, $\mathrm{P}=0.484$ ) and 10-1074 (mean half-life: single $26.7 \pm 4.5$ days $v s$. combined $23.0 \pm 5.4$ days, $\mathrm{P}=0.398$ ).

Evaluating the effects of the combination of $3 \mathrm{BNC117}$ and 101074 on maintaining HIV-1 suppression during ATI, Mendoza et al. (58) enrolled $15 \mathrm{HIV}-1$ infected participants, retrospectively clade $B$ determined, to receive three infusions of $30 \mathrm{mg} / \mathrm{kg}$ each of 3BNC117 and 10-1074 at an interval of three weeks beginning two days before ATI. Time to viral rebound was defined as two consecutive viral loads of $>200 \mathrm{HIV}-1$ RNA copies/mL. Four participants were not included in the efficacy analysis as they developed viral loads of $>20 \mathrm{HIV}-1$ RNA copies/mL before or at the time of the first bNAb-infusion. Infusions were generally well tolerated, and no serious adverse effects were reported. As in HIVuninfected individuals (55-57), the elimination half-lives of 3BNC117 and 10-1074 administered in combination, 17.6 days and 23.2 days respectively, were similar to those observed in previous studies when each antibody was administered alone underlining that the pharmacokinetics of 3BNC117 and 10-1074 are not altered when administered in combination. The combination of 3BNC117 and 10-1074 delayed viral rebound for a median of 21 weeks among the 11 participants who maintained viral suppression ( $<20 \mathrm{HIV}-1$ RNA copies/mL) during the screening period and at day 0 . Historical controls who received monotherapy with two or four 3BNC117 infusions experienced a delay in viral rebound of 6.7 and 9.9 weeks respectively (59).

Circulating HIV-1 variants present during active infection complicate viral control in viremic individuals compared to sustaining viral suppression in ART-treated individuals during ATI. In seven viremic clade B HIV-1-infected individuals (mean viral load > 11,494 HIV-1 RNA copies/mL), 3BNC117 and 10-1074 were administered in combination at either a single infusion of 30 $\mathrm{mg} / \mathrm{kg}$ or three infusions every two weeks (60). When compared to a single infusion with either antibody 3BNC117 (56) or 10-1074 (57), the combination showed prolonged viral suppression $(\mathrm{P}=0.00018)$.
Viremia remained significantly reduced until day 86 with an average drop in viral load for all viremic individuals of $1.65 \log _{10}$ copies $/ \mathrm{mL}$.

The combination of 3BNC117 and 10-1074 induce sufficient viral suppression in sensitive individuals suggesting that viral replication can be limited by this combination. Particularly, viral rebound was not observed when the concentrations of both antibodies were above $10 \mu \mathrm{g} / \mathrm{mL}(58,60)$.

Tuyishime et al. (61) analyzed the potency and breadth of ADCC-competent bNAb and non-neutralizing antibody (nNAb) combinations in an in vitro system using concentrations of $\leq 1 \mu \mathrm{g}$ / $\mathrm{mL}$. In order to best replicate the effects of the combinations in vivo, an autologous in vitro system with CD4+ T cells, infected with latent reservoir HIV-1 viruses (LRVs) from 10 chronically infected individuals, as target cells and autologous purified NK cells as effector cells was used. All LRVs were classified as clade B. Different combinations of bNAbs targeting non-overlapping epitopes expressed on the HIV-1 Env spike protein as well as on the surface of infected cells were evaluated as well as the nNAb A32. Within two hours the combination of three antibodies mediated more than $30 \%$ killing of infected cells, with the combination of the nNAb A32 (C1C2) and the two bNAbs DH511.2K3 (MPER) and PGT121 (V3) being most effective. The same combination was able to eliminate reactivated latently HIV-1 infected cells in an ex vivo quantitative viral outgrowth assay.

The combination of two or more anti-HIV-1-antibodies targeting multiple viral epitopes may be able to overcome viral resistance and increase the efficacy of virus neutralization and ADCC-mediated elimination of latently infected cells when administered in combination with LRAs. In a phase 1 trial 3BNC117 combined with 10-1074 administered over seven infusions at a dose of $30 \mathrm{mg} / \mathrm{kg}$ is currently being evaluated for safety and antiretroviral activity in HIV-1 infected individuals on ART during ATI (NCT03526848).

\section{MODIFIED bNAbs IN HIV-1 CURE}

The plasma half-life of monoclonal IgG antibodies is closely related to the degree with which the antibody binds the neonatal Fc-receptor. Modifications to the constant $(\mathrm{Fc})$ region on antibodies can therefore be made to alter the half-life of antibodies. In a phase 1 dose-escalation study safety and pharmacokinetics were evaluated for VRC01LS - a modified version of the CD4-binding bNAb VRC01 - in HIV-negative adults (62). VRC01LS is modified with two amino acid changes in the $\mathrm{Fc}$ region (M428L and N434S) in order to obtain a longer serum half-life. The modified VRC01LS demonstrated a fourfold increase in elimination half-life $\left(t_{1 / 2}=66 \pm 24\right.$ days $)$ compared to historical data for $\operatorname{VRC01}\left(\mathrm{t}_{1 / 2}=15\right.$ days) (63). The LS mutation does not impact binding to the FcyRIII and thus retains the ability to induce Fc-mediated $\operatorname{ADCC}(64,65)$. Other studies in NHPs confirm these findings (66), indicating that the LS mutation could potentially provide improved efficacy of neutralizing antibodies with less frequent dosing and a lower dose regimen. Additional phase 1 trials are currently evaluating safety, pharmacokinetics and antiviral activity of VRC01LS in HIV-1 infected or uninfected individuals (NCT02797171, 
NCT02840474, NCT02256631) as well as the combination of 3BNC117-LS and 10-1074-LS (NCT04250636).

Technological advances have also made it possible to modify the Fc region of monoclonal antibodies to enhance specific antibodydependent effector functions. The Fc region can be engineered to have higher affinity for human FcyRIII which has been shown to increase ADCC. In fact, GS-9722 - a Fc-modified version of the V3loop binding bNAb PGT121 - has been developed specifically for HIV cure purposes (67). The optimization process identified mutations that enhanced binding to activating Fc $\gamma$ Rs as well as the neonatal Fc-receptor. The resulting antibody demonstrated significantly enhanced killing of HIV infected CD4+ T-cells by primary NK cells isolated from human donors (mean values: Emax $=71 \%$, EC50 $=0.23 \mu \mathrm{g} / \mathrm{mL}$ ) compared to PGT121 (mean values: Emax $=11 \%, \mathrm{EC} 50=3.4 \mu \mathrm{g} / \mathrm{mL}$ ). The Fab mutations had minimal impact on neutralization breadth or potency when tested against a panel of clade B viruses. GS-9722 (Elipovimab) is now in phase 1 clinical testing.

Multiple virological assays have been developed to detect levels of reactivable virus in latent cells on ART, in order to evaluate the success of an intervention in clinical trials but the correlation of these reservoir measures with time to viral rebound is not very strong. Time to viral rebound remains the best and clinically most relevant indicator of intervention efficacy. Interestingly, Offersen et al. (68) were able to show that HIV-1 specific antibody Fc Ngalactosylation (glycosylation) is associated with viral rebound after ATI across three independent HIV cohorts. The mechanistical involvement of these glycosylated gp120 Env specific antibodies in viral control remains unclear and only antibody-dependent neutrophil phagocytosis (ADNP) and ADCD were linked to rebound time in this study. Although NK-mediated ADCC was not found to predict viral rebound time, others have pointed to NK cell activation as an important predictor of time to viral rebound in NHPs in a study that tested a combined LRA and bNAbs HIV cure approach (19). In addition to the emerging association of antibody glycosylation changes with reservoir size across a different independent cohort (69), virus-specific antibody glycosylation may pose an advantageous and simple strategy to track both reservoir size and reactivation.

\section{COMBINATIONS OF bNAbS AND TLR AGONISTS IN HIV-1 CURE}

Both bNAbs and TLR agonists exhibit advantageous properties towards enhancing the killing of HIV-1 infected cells (see Figure 1), however to date only a few studies have investigated the combined effect in vivo. Borducchi et al. (19) evaluated the combined effect of the TLR7 agonist GS-9620 and the V3-glycan dependent bNAb PGT121. Fourty-four NHPs were intrarectally challenged with simian-human immunodeficiency virus (SHIV) and treated with ART from day 7 post-infection. Animals were divided in four groups receiving either sham, GS-9620, PGT121 or a combination. ART was continued for 16 weeks after the last dose of PGT121 to allow for plasma levels of antibodies to drop under the previously determined threshold for neutralization- prevented viral rebound ( $1 \mu \mathrm{g} / \mathrm{mL})(70) .196$ days post ATI only six out of 11 NHPs in the combined PGT121+GS-9620 group experienced viral rebound compared to nine out of 11 in the PGT121 group, 10 out of 11 in the GS-9620 group and 11 out of 11 in the sham group. Viral DNA was undetectable in PBMCs in all groups at week 96, presumably due to early initiation of ART. Notably, viral DNA was detected in LNMCs in all groups with lower levels detected in the PGT121+GS-9620 group at week 120 compared to the sham group $(\mathrm{P}=0.004)$. Despite undetectable viral DNA levels in PBMCs, all sham-treated NHPs rebounded, suggesting that the sensitivity of current viral DNA assays is insufficient to predict viral rebound in line with observations from previous clinical case reports (71).

Adoptive transfer of PBMCs and LNMCs from rebounding NHPs to SHIV-naïve animals resulted in infection, whereas adoptive transfer with cells from non-rebounding NHPs were unable to induce infection. Furthermore, depletion of CD8+ T cells and NK cells in non-rebounding NHPs failed to induce plasma viremia. Although it may be concluded that bNAb administration in combination with immune stimulation with the TLR 7 agonist GS-9620 reduced the viral reservoir, it is important to note that the study used an acute seven-day infection model before ART initiation, which allows for preservation of the host immune system and have been shown to result in a relatively small viral reservoir (72-74). The study observed a maximum therapeutic effect in animals with the lowest pre-ART viral loads suggesting that attaining similar results would be more difficult in animals which started ART during chronic infection.

More recently, Hsu et al. (20) investigated the dual effect of the two bNAbs N6-LS and PGT121 targeting different regions of the HIV-1 Env protein in addition to combinatorial treatment with the TLR7 agonist GS-986. 16 rhesus macaques were infected by intrarectal inoculation with SHIV and started a daily ART regimen on day 14 post-infection. Animals were randomly assigned to an active arm receiving the combination of GS-986, N6-LS and PGT121 or a control arm receiving sham. Animals were monitored for the development of anti-drug antibodies (ADA) against either bNAb and if $\mathrm{ADA}$ developed treatment with the respective $\mathrm{bNAb}$ was suspended. In the active arm ATI was initiated after plasma levels of N6-LS and PGT121 were $<0.25 \mu \mathrm{g} / \mathrm{mL}$ for four weeks, whereas ATI was initiated in all animals in the control arm at week 40.

Consistent with previous studies, GS-986 administration was associated with the induction of peripheral plasma immune activation (17). However, measuring SHIV RNA levels in plasma 24-hours post-GS-986 administration revealed no viral blips. The study observed a strong correlation between SHIV RNA and DNA levels both pre-ART and at the time of ATI suggesting that the level of peak viremia is correlated with the size of the viral reservoir both before and during ART. All animals rebounded, however GS986+N6-LS+PGT121 treatment was associated with delayed time to viral rebound by two-fold with a median time to rebound of three weeks in the control arm and six weeks in the active arm $(\mathrm{P}=0.024)$. Of note only one animal in the active arm received the full number of bNAb infusions as the remaining animals developed anti-drug antibodies (ADA). However, the animal receiving all bNAb infusions did not experience a longer time to viral rebound when 


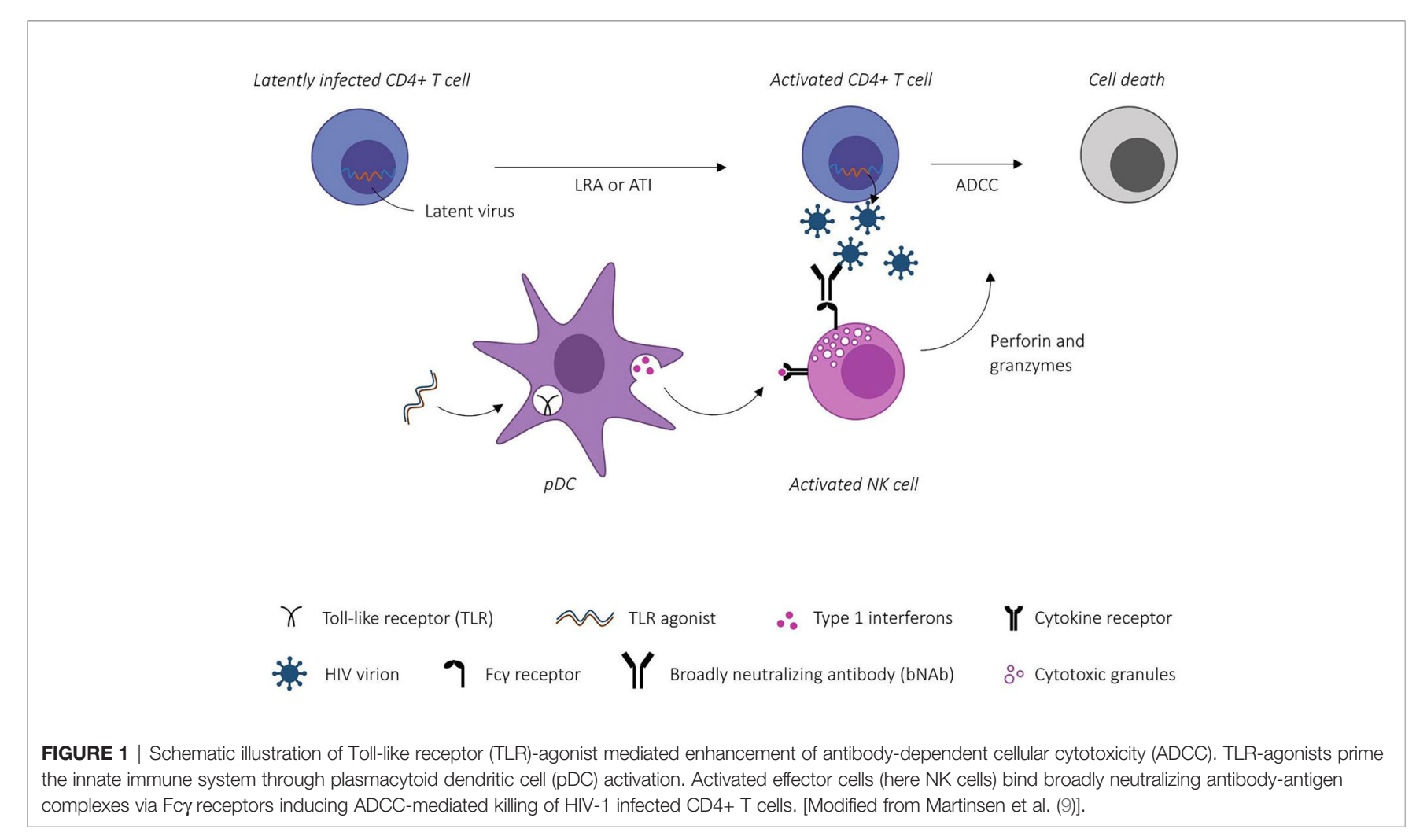

compared to animals that received an incomplete number of infusions. Importantly, this study was able to reproduce findings from Borducchi et al. (19) demonstrating delayed viral rebound after combinatorial treatment with dual bNAbs and a TLR 7 agonist in a different macaque colony using a different SHIV strain but overall, the results were less impressive than those over in the Borducchi paper.

However, the study by Hsu et al. may better reflect a real-life setting where ART initiation is started very early, i.e., day 14 postinoculation compared to extremely early, i.e., 7 days postinoculation in the Borducchi study. This would be similar to the situation in the clinical RV254 acute HIV infection cohort in Thailand (75), hereby potentially translating the impact of this experimental treatment to HIV-infected humans more accurately. The Hsu study is however limited by incomplete study infusions of bNAbs due to the development of ADA, hereby risking an underestimation of the potential treatment effect as well as by the variation in ART duration among the two study arms to accommodate bNAb levels $<0.25 \mu \mathrm{g} / \mathrm{mL}$ before ATI initiation.

\section{CONCLUSIONS}

The preclinical studies included in this review reported beneficial immune stimulation of innate effector functions and enhanced ADCC elimination of HIV-1 infected cells after intervention with either TLR agonists or bNAbs. Although clinical studies evaluating monotherapy with either agent did not observe sustained viral control after ART cessation, findings in two independent NHP-cohorts suggest that combining TLR agonists and bNAbs may delay viral rebound and potentially lead to long-term remission in the absence of ART. Collectively, the clinical studies included in this review indicate that the combination of bNAbs and TLR agonists are well-tolerated and therefore of particular interest for further investigation in clinical HIV-1 cure trials. However, factors such as immune exhaustion, bNAb sensitivity to distinct viral reservoir profiles and time for intervention might affect the clinical success. Indeed, results from two ongoing clinical trials (NCT03837756, NCT04357821) investigating the combination of a TLR 9 agonist (MGN1703) with two bNAbs (3BNC117+10-1074 or VRC07+10-1074) are expected and will shed more light on the potential value of this combination as a means towards an HIV-1 cure.

\section{AUTHOR CONTRIBUTIONS}

$\mathrm{CH}$ and $\mathrm{OS}$ conceived, designed and carried out the project. $\mathrm{CH}$ and OS drafted, reviewed and edited the manuscript. All authors contributed to the article and approved the submitted version.

\section{FUNDING}

This research was supported by The Central Region Denmark Research Fund (grant \#7016-00022B) and The Independent Denmark Research Fund (grant \#A3233). 


\section{REFERENCES}

1. Deeks SG, Lewin SR, Ross AL, Ananworanich J, Benkirane M, Cannon P, et al. International AIDS Society Global Scientific Strategy: Towards an HIV Cure 2016. Nat Med (2016) 22(8):839-50. doi: 10.1038/nm.4108

2. Chun TW, Stuyver L, Mizell SB, Ehler LA, Mican JA, Baseler M, et al. Presence of an Inducible HIV-1 Latent Reservoir During Highly Active Antiretroviral Therapy. Proc Natl Acad Sci USA (1997) 94(24):13193-7. doi: 10.1073/pnas.94.24.13193

3. Finzi D, Hermankova M, Pierson T, Carruth LM, Buck C, Chaisson RE, et al. Identification of a Reservoir for HIV-1 in Patients on Highly Active Antiretroviral Therapy. Sci (New York NY) (1997) 278(5341):1295-300. doi: 10.1126/science.278.5341.1295

4. Siliciano JD, Kajdas J, Finzi D, Quinn TC, Chadwick K, Margolick JB, et al. Long-Term Follow-Up Studies Confirm the Stability of the Latent Reservoir for HIV-1 in Resting CD4+ T Cells. Nat Med (2003) 9(6):727-8. doi: 10.1038/ nm880

5. Crooks AM, Bateson R, Cope AB, Dahl NP, Griggs MK, Kuruc JD, et al. Precise Quantitation of the Latent HIV-1 Reservoir: Implications for Eradication Strategies. J Infect Dis (2015) 212(9):1361-5. doi: 10.1093/ infdis/jiv218

6. Chun TW, Davey RT Jr, Engel D, Lane HC, Fauci AS. Re-Emergence of HIV After Stopping Therapy. Nature (1999) 401(6756):874-5. doi: 10.1038/44755

7. Sengupta S, Siliciano RF. Targeting the Latent Reservoir for HIV-1. Immunity (2018) 48(5):872-95. doi: 10.1016/j.immuni.2018.04.030

8. Alter G, Martin MP, Teigen N, Carr WH, Suscovich TJ, Schneidewind A, et al. Differential Natural Killer Cell-Mediated Inhibition of HIV-1 Replication Based on Distinct KIR/HLA Subtypes. J Exp Med (2007) 204(12):3027-36. doi: $10.1084 /$ jem.20070695

9. Martinsen JT, Gunst JD, Hojen JF, Tolstrup M, Sogaard OS. The Use of TollLike Receptor Agonists in HIV-1 Cure Strategies. Front Immunol (2020) 11:1112. doi: 10.3389/fimmu.2020.01112

10. Stamatatos L, Morris L, Burton DR, Mascola JR. Neutralizing Antibodies Generated During Natural HIV-1 Infection: Good News for an HIV-1 Vaccine? Nat Med (2009) 15(8):866-70. doi: 10.1038/nm.1949

11. Mouquet H. Antibody B Cell Responses in HIV-1 Infection. Trends Immunol (2014) 35(11):549-61. doi: 10.1016/j.it.2014.08.007

12. Bam RA, Hansen D, Irrinki A, Mulato A, Jones GS, Hesselgesser J, et al. TLR7 Agonist GS-9620 Is a Potent Inhibitor of Acute HIV-1 Infection in Human Peripheral Blood Mononuclear Cells. Antimicrob Agents Chemother (2017) 61 (1):e01369-16. doi: 10.1128/AAC.01369-16

13. Tsai A, Irrinki A, Kaur J, Cihlar T, Kukolj G, Sloan DD, et al. Toll-Like Receptor 7 Agonist GS-9620 Induces HIV Expression and HIV-Specific Immunity in Cells From HIV-Infected Individuals on Suppressive Antiretroviral Therapy. J Virol (2017) 91(8):e02166-16. doi: 10.1128/ JVI.02166-16

14. Macedo AB, Novis CL, De Assis CM, Sorensen ES, Moszczynski P, Huang SH, et al. Dual TLR2 and TLR7 Agonists as HIV Latency-Reversing Agents. JCI Insight (2018) 3(19):e122673. doi: 10.1172/jci.insight.122673

15. Offersen R, Nissen SK, Rasmussen TA, Østergaard L, Denton PW, Søgaard OS, et al. A Novel Toll-Like Receptor 9 Agonist, MGN1703, Enhances HIV-1 Transcription and NK Cell-Mediated Inhibition of HIV-1-Infected Autologous CD4+ T Cells. J Virol (2016) 90(9):4441-53. doi: 10.1128/ JVI.00222-16

16. Bekerman E, Hesselgesser J, Carr B, Nagel M, Hung M, Wang A, et al. PD-1 Blockade and TLR7 Activation Lack Therapeutic Benefit in Chronic Simian Immunodeficiency Virus-Infected Macaques on Antiretroviral Therapy. Antimicrob Agents Chemother (2019) 63(11):e01163-19. doi: 10.1128/ AAC.01163-19

17. Lim SY, Osuna CE, Hraber PT, Hesselgesser J, Gerold JM, Barnes TL, et al. TLR7 Agonists Induce Transient Viremia and Reduce the Viral Reservoir in SIV-Infected Rhesus Macaques on Antiretroviral Therapy. Sci Transl Med (2018) 10(439):eaao4521. doi: 10.1126/scitranslmed.aao4521

18. Del Prete GQ, Alvord WG, Li Y, Deleage C, Nag M, Oswald K, et al. TLR7 Agonist Administration to SIV-Infected Macaques Receiving Early Initiated cART Does Not Induce Plasma Viremia. JCI Insight (2019) 4(11):e127717. doi: $10.1172 /$ jci.insight. 127717
19. Borducchi EN, Liu J, Nkolola JP, Cadena AM, Yu WH, Fischinger S, et al. Antibody and TLR7 Agonist Delay Viral Rebound in SHIV-Infected Monkeys. Nature (2018) 563(7731):360-4. doi: 10.1038/s41586-018-0600-6

20. Hsu DC, Schuetz A, Imerbsin R, Silsorn D, Pegu A, Inthawong D, et al. TLR7 Agonist, N6-LS and PGT121 Delayed Viral Rebound in SHIV-Infected Macaques After Antiretroviral Therapy Interruption. PloS Pathog (2021) 17 (2):e1009339. doi: 10.1371/journal.ppat.1009339

21. Riddler SA, Para M, Benson CA, Mills A, Ramgopal M, DeJesus E, et al. Vesatolimod, A Toll-Like Receptor 7 Agonist, Induces Immune Activation in Virally Suppressed Adults With HIV-1. Clin Infect Dis (2020) 72(11):e815-24. doi: 10.1093/cid/ciaa1534

22. Vibholm LK, Konrad CV, Schleimann MH, Frattari G, Winckelmann A, Klastrup V, et al. Effects of 24-Week Toll-Like Receptor 9 Agonist Treatment in HIV Type 1+ Individuals. Aids (2019) 33(8):1315-25. doi: 10.1097/ QAD.0000000000002213

23. Jordan A, Bisgrove D, Verdin E. HIV Reproducibly Establishes a Latent Infection After Acute Infection of T Cells In Vitro. EMBO J (2003) 22 (8):1868-77. doi: 10.1093/emboj/cdg188

24. Cantaert T, Baeten D, Tak PP, van Baarsen LGM. Type I IFN and Tnf $\alpha$ CrossRegulation in Immune-Mediated Inflammatory Disease: Basic Concepts and Clinical Relevance. Arthritis Res Ther (2010) 12(5):219. doi: 10.1186/ar3150

25. Hornung V, Rothenfusser S, Britsch S, Krug A, Jahrsdörfer B, Giese T, et al. Quantitative Expression of Toll-Like Receptor 1-10 mRNA in Cellular Subsets of Human Peripheral Blood Mononuclear Cells and Sensitivity to CpG Oligodeoxynucleotides. J Immunol (2002) 168(9):4531-7. doi: 10.4049/ jimmunol.168.9.4531

26. Adib-Conquy M, Scott-Algara D, Cavaillon J-M, Souza-Fonseca-Guimaraes F. TLR-Mediated Activation of NK Cells and Their Role in Bacterial/Viral Immune Responses in Mammals. Immunol Cell Biol (2014) 92(3):256-62. doi: 10.1038/icb.2013.99

27. Dupuy FP, Kant S, Barbe A, Routy JP, Bruneau J, Lebouche B, et al. AntibodyDependent Cellular Cytotoxicity-Competent Antibodies Against HIV-1Infected Cells in Plasma From HIV-Infected Subjects. mBio (2019) 10(6): e02690-19. doi: 10.1128/mBio.02690-19

28. Bruel T, Guivel-Benhassine F, Amraoui S, Malbec M, Richard L, Bourdic K, et al. Elimination of HIV-1-Infected Cells by Broadly Neutralizing Antibodies. Nat Commun (2016) 7:10844. doi: 10.1038/ncomms10844

29. von Bredow B, Arias JF, Heyer LN, Moldt B, Le K, Robinson JE, et al. Comparison of Antibody-Dependent Cell-Mediated Cytotoxicity and Virus Neutralization by HIV-1 Env-Specific Monoclonal Antibodies. J Virol (2016) 90(13):6127-39. doi: 10.1128/JVI.00347-16

30. Mujib S, Liu J, Rahman A, Schwartz JA, Bonner P, Yue FY, et al. Comprehensive Cross-Clade Characterization of Antibody-Mediated Recognition, Complement-Mediated Lysis, and Cell-Mediated Cytotoxicity of HIV-1 Envelope-Specific Antibodies Toward Eradication of the HIV-1 Reservoir. J Virol (2017) 91(16):e00634-17. doi: 10.1128/JVI.00634-17

31. Ren Y, Korom M, Truong R, Chan D, Huang SH, Kovacs CC, et al. Susceptibility to Neutralization by Broadly Neutralizing Antibodies Generally Correlates With Infected Cell Binding for a Panel of Clade B HIV Reactivated From Latent Reservoirs. J Virol (2018) 92(23):e00895-18. doi: 10.1128/JVI.00895-18

32. Flerin NC, Bardhi A, Zheng JH, Korom M, Folkvord J, Kovacs C, et al. Establishment of a Novel Humanized Mouse Model To Investigate In Vivo Activation and Depletion of Patient-Derived HIV Latent Reservoirs. J Virol (2019) 93(6):e02051-18. doi: 10.1128/JVI.02051-18

33. Lu CL, Murakowski DK, Bournazos S, Schoofs T, Sarkar D, Halper-Stromberg A, et al. Enhanced Clearance of HIV-1-Infected Cells by Broadly Neutralizing Antibodies Against HIV-1 In Vivo. Science (New York NY) (2016) 352 (6288):1001-4. doi: 10.1126/science.aaf1279

34. Crowell TA, Colby DJ, Pinyakorn S, Sacdalan C, Pagliuzza A, Intasan J, et al. Safety and Efficacy of VRC01 Broadly Neutralising Antibodies in Adults With Acutely Treated HIV (RV397): A Phase 2, Randomised, Double-Blind, Placebo-Controlled Trial. Lancet HIV (2019) 6(5):e297-306. doi: 10.1016/ S2352-3018(19)30053-0

35. Riddler SA, Zheng L, Durand CM, Ritz J, Koup RA, Ledgerwood J, et al. Randomized Clinical Trial to Assess the Impact of the Broadly Neutralizing HIV-1 Monoclonal Antibody VRC01 on HIV-1 Persistence in Individuals on 
Effective ART. Open Forum Infect Dis (2018) 5(10):ofy242. doi: 10.1093/ofid/ ofy 242

36. Richardson SI, Chung AW, Natarajan H, Mabvakure B, Mkhize NN, Garrett $\mathrm{N}$, et al. HIV-Specific Fc Effector Function Early in Infection Predicts the Development of Broadly Neutralizing Antibodies. PloS Pathog (2018) 14(4): e1006987. doi: 10.1371/journal.ppat.1006987

37. Pollara J, Hart L, Brewer F, Pickeral J, Packard BZ, Hoxie JA, et al. HighThroughput Quantitative Analysis of HIV-1 and SIV-Specific ADCCMediating Antibody Responses. Cytometry A (2011) 79A(8):603-12. doi: 10.1002/cyto.a.21084

38. Gómez-Román VR, Florese RH, Patterson LJ, Peng B, Venzon D, Aldrich K, et al. A Simplified Method for the Rapid Fluorometric Assessment of Antibody-Dependent Cell-Mediated Cytotoxicity. J Immunol Methods (2006) 308(1):53-67. doi: 10.1016/j.jim.2005.09.018

39. Kramski M, Schorcht A, Johnston APR, Lichtfuss GF, Jegaskanda S, De Rose $\mathrm{R}$, et al. Role of Monocytes in Mediating HIV-Specific Antibody-Dependent Cellular Cytotoxicity. J Immunol Methods (2012) 384(1):51-61. doi: 10.1016/ j.jim.2012.07.006

40. Richard J, Prévost J, Baxter AE, von Bredow B, Ding S, Medjahed H, et al. Uninfected Bystander Cells Impact the Measurement of HIV-Specific Antibody-Dependent Cellular Cytotoxicity Responses. mBio (2018) 9(2): e00358-18. doi: 10.1128/mBio.00358-18

41. Calarese DA, Scanlan CN, Zwick MB, Deechongkit S, Mimura Y, Kunert R, et al. Antibody Domain Exchange Is an Immunological Solution to Carbohydrate Cluster Recognition. Science (2003) 300(5628):2065-71. doi: 10.1126/science. 1083182

42. West AP, Galimidi RP, Foglesong CP, Gnanapragasam PNP, Huey-Tubman KE, Klein JS, et al. Design and Expression of a Dimeric Form of Human Immunodeficiency Virus Type 1 Antibody 2G12 With Increased Neutralization Potency. J Virol (2009) 83: (1):98-104. doi: 10.1128/JVI.01564-08

43. Tu T, Zhan J, Mou D, Li W, Su B, Zhang T, et al. In Vitro Inhibition of HIV-1 Replication in Autologous CD4(+) T Cells Indicates Viral Containment by Multifactorial Mechanisms. Virol Sin (2017) 32(6):485-94. doi: 10.1007/ s12250-017-3992-9

44. Seaman MS, Janes H, Hawkins N, Grandpre LE, Devoy C, Giri A, et al. Tiered Categorization of a Diverse Panel of HIV-1 Env Pseudoviruses for Assessment of Neutralizing Antibodies. J Virol (2010) 84(3):1439-52. doi: 10.1128/ JVI.02108-09

45. Salazar-Gonzalez JF, Salazar MG, Keele BF, Learn GH, Giorgi EE, Li H, et al. Genetic Identity, Biological Phenotype, and Evolutionary Pathways of Transmitted/Founder Viruses in Acute and Early HIV-1 Infection. J Exp Med (2009) 206(6):1273-89. doi: 10.1084/jem.20090378

46. Burton DR, Mascola JR. Antibody Responses to Envelope Glycoproteins in HIV-1 Infection. Nat Immunol (2015) 16(6):571-6. doi: 10.1038/ni.3158

47. Lu LL, Suscovich TJ, Fortune SM, Alter G. Beyond Binding: Antibody Effector Functions in Infectious Diseases. Nat Rev Immunol (2018) 18(1):46-61. doi: 10.1038/nri.2017.106

48. Suryawanshi P, Bagul R, Shete A, Thakar M. Anti-HIV-1 ADCC and HIV-1 Env Can Be Partners in Reducing Latent HIV Reservoir. Front Immunol (2021) 12:663919. doi: 10.3389/fimmu.2021.663919

49. Smalls-Mantey A, Connors M, Sattentau QJ. Comparative Efficiency of HIV1-Infected T Cell Killing by NK Cells, Monocytes and Neutrophils. PloS One (2013) 8(9):e74858. doi: 10.1371/journal.pone.0074858

50. Yaffe ZA, Naiman NE, Slyker J, Wines BD, Richardson BA, Hogarth PM, et al. Improved HIV-Positive Infant Survival Is Correlated With High Levels of HIV-Specific ADCC Activity in Multiple Cohorts. Cell Rep Med (2021) 2 (4):100254. doi: 10.1016/j.xcrm.2021.100254

51. Duchemin M, Khamassi M, Xu L, Tudor D, Bomsel M. IgA Targeting Human Immunodeficiency Virus-1 Envelope Gp41 Triggers Antibody-Dependent Cellular Cytotoxicity Cross-Clade and Cooperates With Gp41-Specific IgG to Increase Cell Lysis. Front Immunol (2018) 9:244. doi: 10.3389/ fimmu.2018.00244

52. Tomaras GD, Ferrari G, Shen X, Alam SM, Liao H-X, Pollara J, et al. VaccineInduced Plasma IgA Specific for the C1 Region of the HIV-1 Envelope Blocks Binding and Effector Function of IgG. Proc Natl Acad Sci USA (2013) 110 (22):9019-24. doi: 10.1073/pnas.1301456110

53. Ruiz MJ, Ghiglione Y, Falivene J, Laufer N, Holgado MP, Socías ME, et al. Env-Specific IgA From Viremic HIV-Infected Subjects Compromises
Antibody-Dependent Cellular Cytotoxicity. J Virol (2016) 90(2):670-81. doi: 10.1128/JVI.02363-15

54. Parsons MS, Lee WS, Kristensen AB, Amarasena T, Khoury G, Wheatley AK, et al. Fc-Dependent Functions Are Redundant to Efficacy of Anti-HIV Antibody PGT121 in Macaques. J Clin Invest (2019) 129(1):182-91. doi: 10.1172/JCI122466

55. Cohen YZ, Butler AL, Millard K, Witmer-Pack M, Levin R, Unson-O’Brien C, et al. Safety, Pharmacokinetics, and Immunogenicity of the Combination of the Broadly Neutralizing Anti-HIV-1 Antibodies 3BNC117 and 10-1074 in Healthy Adults: A Randomized, Phase 1 Study. PloS One (2019) 14(8): e0219142. doi: 10.1371/journal.pone.0219142

56. Caskey M, Klein F, Lorenzi JC, Seaman MS, West APJr., Buckley N, et al. Viraemia Suppressed in HIV-1-Infected Humans by Broadly Neutralizing Antibody 3BNC117. Nature (2015) 522(7557):487-91. doi: 10.1038/ nature14411

57. Caskey M, Schoofs T, Gruell H, Settler A, Karagounis T, Kreider EF, et al. Antibody 10-1074 Suppresses Viremia in HIV-1-Infected Individuals. Nat Med (2017) 23(2):185-91. doi: 10.1038/nm.4268

58. Mendoza P, Gruell H, Nogueira L, Pai JA, Butler AL, Millard K, et al. Combination Therapy With Anti-HIV-1 Antibodies Maintains Viral Suppression. Nature (2018) 561(7724):479-84. doi: 10.1038/s41586-0180531-2

59. Scheid JF, Horwitz JA, Bar-On Y, Kreider EF, Lu CL, Lorenzi JC, et al. HIV-1 Antibody 3BNC117 Suppresses Viral Rebound in Humans During Treatment Interruption. Nature (2016) 535(7613):556-60. doi: 10.1038/nature18929

60. Bar-On Y, Gruell H, Schoofs T, Pai JA, Nogueira L, Butler AL, et al. Safety and Antiviral Activity of Combination HIV-1 Broadly Neutralizing Antibodies in Viremic Individuals. Nat Med (2018) 24(11):1701-7. doi: 10.1038/s41591018-0186-4

61. Tuyishime M, Garrido C, Jha S, Moeser M, Mielke D, LaBranche C, et al. Improved Killing of HIV-Infected Cells Using Three Neutralizing and NonNeutralizing Antibodies. J Clin Invest (2020) 130(10):5157-70. doi: 10.1172/ JCI135557

62. Gaudinski MR, Coates EE, Houser KV, Chen GL, Yamshchikov G, Saunders JG, et al. Safety and Pharmacokinetics of the Fc-Modified HIV-1 Human Monoclonal Antibody VRC01LS: A Phase 1 Open-Label Clinical Trial in Healthy Adults. PloS Med (2018) 15(1):e1002493. doi: 10.1371/journal.pmed.1002493

63. Ledgerwood JE, Coates EE, Yamshchikov G, Saunders JG, Holman L, Enama ME, et al. Safety, Pharmacokinetics and Neutralization of the Broadly Neutralizing HIV-1 Human Monoclonal Antibody VRC01 in Healthy Adults. Clin Exp Immunol (2015) 182(3):289-301. doi: 10.1111/cei.12692

64. Ko SY, Pegu A, Rudicell RS, Yang ZY, Joyce MG, Chen X, et al. Enhanced Neonatal Fc Receptor Function Improves Protection Against Primate SHIV Infection. Nature (2014) 514(7524):642-5. doi: 10.1038/nature13612

65. Asokan M, Dias J, Liu C, Maximova A, Ernste K, Pegu A, et al. Fc-Mediated Effector Function Contributes to the In Vivo Antiviral Effect of an HIV Neutralizing Antibody. Proc Natl Acad Sci USA (2020) 117(31):18754-63. doi: 10.1073/pnas.2008236117

66. Gautam R, Nishimura Y, Pegu A, Nason MC, Klein F, Gazumyan A, et al. A Single Injection of Anti-HIV-1 Antibodies Protects Against Repeated SHIV Challenges. Nature (2016) 533(7601):105-9. doi: 10.1038/nature17677

67. Thomsen ND BM, Pace CS, Zhang X, Hung M, Nagel MR, Carr BA, et al. Foster City, CA, USA. GS-9722: First-In-Class Effector-Enhanced Broadly Neutralizing Antibody for HIV Cure In: HIV Curative Approaches: Antibodies And CAR-TCell; The annual Conference on Retroviruses and Opportunistic Infections (CROI), CROI e-abstract, Seattle, Washington, (2019). Available at: https://www. croiconference.org.

68. Offersen R, Yu WH, Scully EP, Julg B, Euler Z, Sadanand S, et al. HIV Antibody Fc N-Linked Glycosylation Is Associated With Viral Rebound. Cell Rep (2020) 33(11):108502. doi: 10.1016/j.celrep.2020.108502

69. Vadrevu SK, Trbojevic-Akmacic I, Kossenkov AV, Colomb F, Giron LB, Anzurez A, et al. Frontline Science: Plasma and Immunoglobulin G Galactosylation Associate With HIV Persistence During Antiretroviral Therapy. J Leukoc Biol (2018) 104(3):461-71. doi: 10.1002/JLB.3HI1217-500R

70. Barouch DH, Whitney JB, Moldt B, Klein F, Oliveira TY, Liu J, et al. Therapeutic Efficacy of Potent Neutralizing HIV-1-Specific Monoclonal Antibodies in SHIV-Infected Rhesus Monkeys. Nature (2013) 503 (7475):224-8. doi: 10.1038/nature12744 
71. Henrich TJ, Hanhauser E, Marty FM, Sirignano MN, Keating S, Lee TH, et al. Antiretroviral-Free HIV-1 Remission and Viral Rebound After Allogeneic Stem Cell Transplantation: Report of 2 Cases. Ann Intern Med (2014) 161 (5):319-27. doi: 10.7326/M14-1027

72. Archin NM, Vaidya NK, Kuruc JD, Liberty AL, Wiegand A, Kearney MF, et al. Immediate Antiviral Therapy Appears to Restrict Resting CD4+ Cell HIV-1 Infection Without Accelerating the Decay of Latent Infection. Proc Natl Acad Sci USA (2012) 109(24):9523-8. doi: 10.1073/pnas.1120248109

73. Buzon MJ, Martin-Gayo E, Pereyra F, Ouyang Z, Sun H, Li JZ, et al. LongTerm Antiretroviral Treatment Initiated at Primary HIV-1 Infection Affects the Size, Composition, and Decay Kinetics of the Reservoir of HIV-1-Infected CD4 T Cells. J Virol (2014) 88(17):10056-65. doi: 10.1128/JVI.01046-14

74. Ananworanich J, Dubé K, Chomont N. How Does the Timing of Antiretroviral Therapy Initiation in Acute Infection Affect HIV Reservoirs? Curr Opin HIV AIDS (2015) 10(1):18-28. doi: 10.1097/COH.0000000000000122

75. Crowell TA, Phanuphak N, Pinyakorn S, Kroon E, Fletcher JLK, Colby D, et al. Virologic Failure Is Uncommon After Treatment Initiation During Acute HIV Infection. AIDS (2016) 30(12):1943-50. doi: 10.1097/QAD. 0000000000001148
Conflict of Interest: OS has served as a scientific advisor for Abbvie, Gilead, Mologen AG, and Immunocore for work unrelated to this project.

The remaining author declares that the research was conducted in the absence of any commercial or financial relationships that could be construed as a potential conflict of interest.

Publisher's Note: All claims expressed in this article are solely those of the authors and do not necessarily represent those of their affiliated organizations, or those of the publisher, the editors and the reviewers. Any product that may be evaluated in this article, or claim that may be made by its manufacturer, is not guaranteed or endorsed by the publisher.

Copyright (c) 2021 Hvilsom and Søgaard. This is an open-access article distributed under the terms of the Creative Commons Attribution License (CC BY). The use, distribution or reproduction in other forums is permitted, provided the original author(s) and the copyright owner(s) are credited and that the original publication in this journal is cited, in accordance with accepted academic practice. No use, distribution or reproduction is permitted which does not comply with these terms. 